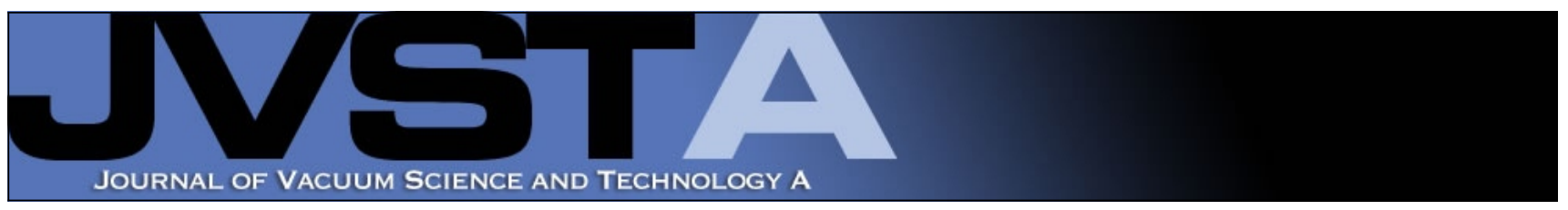

\title{
Experimental evaluation of an adaptive Joule-Thomson cooling system including silicon-microfabricated heat exchanger and microvalve components
}

Weibin Zhu, Jong M. Park, Michael J. White, Gregory F. Nellis, and Yogesh B. Gianchandani

Citation: J. Vac. Sci. Technol. A 29, 021005 (2011); doi: 10.1116/1.3545917

View online: http://dx.doi.org/10.1116/1.3545917

View Table of Contents: http://avspublications.org/resource/1/JVTAD6/v29/i2

Published by the AVS: Science \& Technology of Materials, Interfaces, and Processing

\section{Related Articles}

3D stepped electrodes on a flexible substrate with permanently bonded poly(dimethylsiloxane) channels for moving microfluid

J. Vac. Sci. Technol. B 31, 022002 (2013)

Effect of neutral beam etching on mechanical property of microcantilevers

J. Vac. Sci. Technol. B 31, 022001 (2013)

Piezoelectrically transduced silicon carbide MEMS double-clamped beam resonators

J. Vac. Sci. Technol. B 30, 06FD05 (2012)

Nanomechanical tuning forks fabricated using focused-ion-beam chemical vapor deposition

J. Vac. Sci. Technol. B 30, 06FD03 (2012)

Bimaterial electromechanical systems for a biomimetical acoustic sensor

J. Vac. Sci. Technol. B 30, 06FD01 (2012)

\section{Additional information on J. Vac. Sci. Technol. A}

Journal Homepage: http://avspublications.org/jvsta

Journal Information: http://avspublications.org/jvsta/about/about_the_journal

Top downloads: http://avspublications.org/jvsta/top_20_most_downloaded

Information for Authors: http://avspublications.org/jvsta/authors/information_for_contributors

\section{ADVERTISEMENT}

\section{Instruments for advanced science}
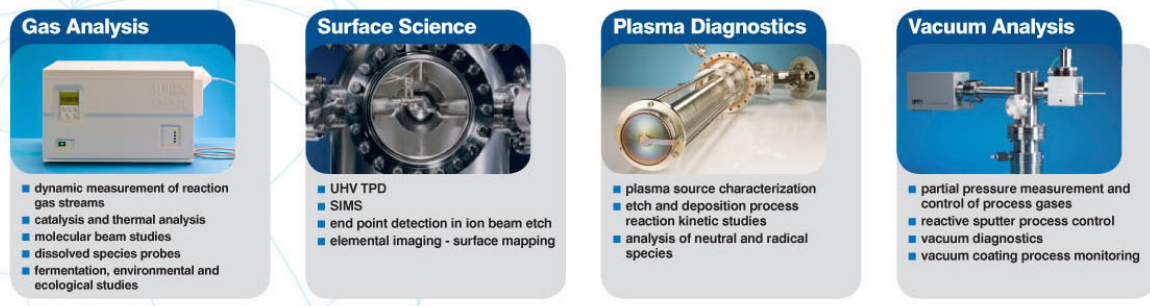

contact Hiden Analytical for further details

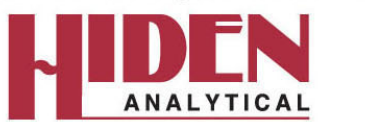

info@hideninc.com

www.HidenAnalytical.com

CLICK to view our product catalogue 


\title{
Experimental evaluation of an adaptive Joule-Thomson cooling system including silicon-microfabricated heat exchanger and microvalve components
}

\author{
Weibin Zhu ${ }^{\text {a) }}$ \\ Department of Mechanical Engineering, University of Michigan, 2350 Hayward Street, Ann Arbor, \\ Michigan 48109-2125 \\ Jong M. Park \\ Department of Electrical Engineering and Computer Science, University of Michigan, 1301 Beal Avenue, \\ Ann Arbor, Michigan 48109-2122 \\ Michael J. White and Gregory F. Nellis \\ Department of Mechanical Engineering, University of Wisconsin, Madison, Wisconsin 53706-1687 \\ Yogesh B. Gianchandani \\ Department of Mechanical Engineering, University of Michigan, 2350 Hayward Street, Ann Arbor, \\ Michigan 48109-2125 and Department of Electrical Engineering and Computer Science, \\ University of Michigan, 1301 Beal Avenue, Ann Arbor, Michigan 48109-2122
}

(Received 17 August 2010; accepted 4 January 2011; published 21 January 2011)

\begin{abstract}
This article reports the evaluation of a Joule-Thomson (JT) cooling system that combines two custom micromachined components-a Si/glass-stack recuperative heat exchanger and a piezoelectrically actuated expansion microvalve. With the microvalve controlling the flow rate, this system can modulate cooling to accommodate varying refrigeration loads. The perforated plate $\mathrm{Si} / \mathrm{glass}$ heat exchanger is fabricated with a stack of alternating silicon plates and Pyrex glass spacers. The microvalve utilizes a lead zirconate titanate actuator to push a Si micromachined valve seat against a glass plate, thus modulating the flow passing through the gap between the valve seat and the glass plate. The fabricated heat exchanger has a footprint of $1 \times 1 \mathrm{~cm}^{2}$ and a length of 35 $\mathrm{mm}$. The size of the micromachined piezoelectrically actuated valve is about $1 \times 1 \times 1 \mathrm{~cm}^{3}$. In JT cooling tests, the temperature of the system was successfully controlled by adjusting the input voltage of the microvalve. When the valve was fully opened (at an input voltage of $-30 \mathrm{~V}$ ), the system cooled down to a temperature as low as $254.5 \mathrm{~K}$ at $430 \mathrm{kPa}$ pressure difference between inlet and outlet at steady state and $234 \mathrm{~K}$ at $710 \mathrm{kPa}$ in a transient state. The system provided cooling powers of $75 \mathrm{~mW}$ at $255 \mathrm{~K}$ and $150 \mathrm{~mW}$ at $258 \mathrm{~K}$. Parasitic heat loads at $255 \mathrm{~K}$ are estimated at approximately 700 mW. (C) 2011 American Vacuum Society. [DOI: 10.1116/1.3545917]
\end{abstract}

\section{INTRODUCTION}

Applications for cryogenic microsystems, which range from the cooling of vacuum microenvironments for material growth and analysis, optical detectors that are deployed in space $^{1-3}$ to cryosurgery, ${ }^{4-8}$ have a number of requirements. For example, many such systems must maintain high stability at various cryogenic temperatures. While providing sufficient cooling power, the systems should have small size and weight. For the space applications, this is primarily motivated by cost of launching the equipment into space. For the cryosurgical applications, this is necessary to minimize the invasiveness of the procedure and is also motivated by cost and convenience, i.e., a portable, small instrument with low manufacturing and operating cost is desired.

Due to the absence of cold moving parts and the consequent potential for high reliability, Joule-Thomson (JT) coolers are suitable for miniaturization and can be implemented with simple structures that are compatible with silicon/glass

\footnotetext{
a) Author to whom correspondence should be addressed; electronic mail:
} zhuwb@umich.edu microfabrication. Compared to traditional JT coolers that use metals, a micromachined silicon/glass JT cooler is attractive because it can accommodate integrated sensors while still providing high thermodynamic efficiency and low cost mass production. Furthermore, the potential for magnetic resonance imaging compatibility makes Si/glass JT coolers attractive for cryosurgical tools.

In a JT system, often, the cooling is adjusted by using a heater to consume excessive cooling power; hence, cooling power is wasted and the total energy consumption is increased. Alternate means of accommodating varying loads and target temperatures are beneficial. In an alternative approach (Fig. 1) that is less wasteful of energy, cold, highpressure fluid leaving a recuperative counterflow heat exchanger expands through an adjustable valve. This is potentially cost effective in applications that demand cooling units for multiple locations with different target temperatures because only one compressor is necessary and the total size and weight of the systems are tremendously reduced. For example, in a distributed cooling network, many similar JT cooling units can be installed in parallel and the refrigerant is 


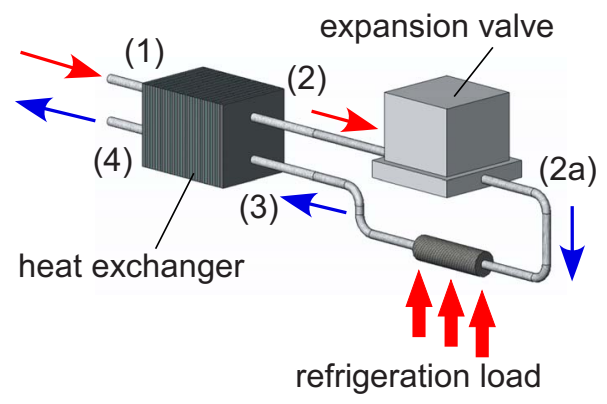

FIG. 1. (Color online) In a JT system, high-pressure, hot fluid at state (1) passing through a counterflow recuperative heat exchanger is precooled by the low-pressure, cold fluid returning from the refrigeration load. The cooled high-pressure fluid leaving the heat exchanger at state (2) expands through a valve and reaches a low temperature at state (2a) due to the JT effect. The cold, low-pressure fluid flows through the heat load, where it is warmed by the refrigeration load and reaches state (3). It is fed back into the heat exchanger and warmed to state (4).

distributed to these units from an external compressor. The expansion microvalve can modulate the flow rate of refrigerant and, as a result, precisely control each cooling unit. Furthermore, when operated only in the vapor phase or with mixed gas the valve can be used to modulate temperature and flow rate. Ultimately, a temperature sensor at the cold end can be used to measure the temperature and servocontrol the microvalve aperture.

Micromachined cryocoolers ${ }^{9-12}$ have been developed to cool small integrated circuits to cryogenic temperatures in order to improve signal-to-noise ratio and the speed of the system. However, many of these coolers provide cooling power limited to the milliwatt range, which is insufficient for many space applications and cryosurgical applications. This article reports a JT cooling system that integrates a micromachined Si/glass-stack recuperative heat exchanger and a piezoelectrically actuated expansion microvalve. (Portions of this work have been reported in conference abstract form by Zhu et al. ${ }^{13}$ ) The temperature at the cold end of the system can be adjusted by modulating the opening of the microvalve. This system can accommodate higher heat loads and has potential utility in distributed cooling networks for space applications, or in cryosurgical applications, without the requirement of heaters for temperature control.

\section{DESIGN AND FABRICATION OF COMPONENTS}

The core components of a JT system are the counterflow heat exchanger and the expansion microvalve. The system utilizes a micromachined Si/glass perforated plate counterflow heat exchanger ${ }^{14}$ and a piezoelectrically actuated expansion valve; ${ }^{15}$ these two components were separately evaluated in different contexts. This section summarizes the essential design and fabrication aspects of both components.

There are two major requirements for an efficient counterflow microheat exchanger. (1) Good heat conductance between the hot and the cold streams is necessary in order for the incoming high-pressure refrigerant to be precooled by the outgoing refrigerant. Materials and structures that provide high heat transfer conductance between the two streams are

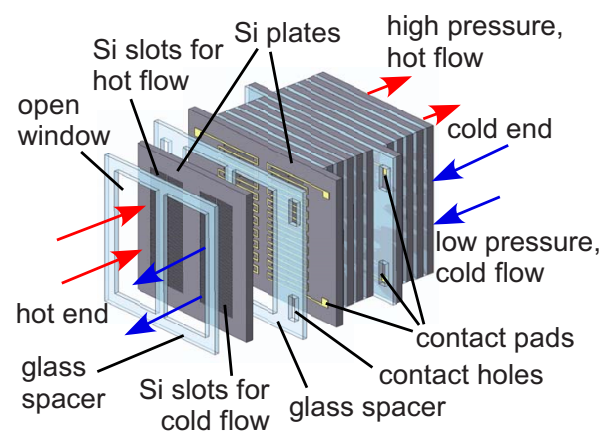

(a)

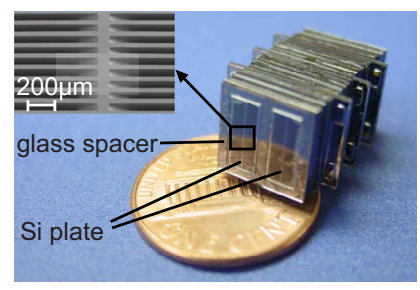

(b)

FIG. 2. (Color online) Perforated plate counterflow heat exchanger: (a) schematic diagram and (b) photograph of the fabricated device with an inset close-up SEM image of the Si slots. The heat exchanger is divided into two regions: a hot region, where the hot flow (from left to right, in red) passes through one side of the Si plates and the glass spacers, and a cold region, where the cold flow (from right to left, in blue) passes through the other side in an opposite direction. The glass spacers are bonded to the adjacent $\mathrm{Si}$ plates in order to allow a good seal between two regions and to prevent leakage from each region to the ambient. The footprint of the micromachined perforated plate heat exchanger is $1 \times 1 \mathrm{~cm}^{2}$ and the length shown in this figure is about $20 \mathrm{~mm}$ ( 25 dies). The longest fabricated heat exchanger was about $35 \mathrm{~mm}$ long (43 dies). The thickness of each Si plate is $500 \mu \mathrm{m}$, and the thickness of each glass spacer is $300 \mu \mathrm{m}$. The two sets of slots that are visible in the Si plate are the ends of the high-pressure and low-pressure flow channels.

required. Structures that provide a high ratio of heat transfer area to volume can enhance heat transfer between the fluid and the heat exchanger surface area. However, the resulting increase in the streamwise pressure drop must be taken into account in the design. (2) The streamwise heat conduction inside the heat exchanger should be small. Heat conduction along the fluid direction can reduce the temperature gradient between cold end and hot end.

The Si/glass heat exchanger [Fig. 2(a)] is comprised of a stack of alternating silicon plates and Pyrex glass spacers. The thermal conductivity of single crystal $\mathrm{Si}$ is about 150 $\mathrm{W} / \mathrm{m} \mathrm{K}$ at room temperature, but also depends on doping level and temperature. The thermal conductivity of Pyrex is about $1.4 \mathrm{~W} / \mathrm{m} \mathrm{K}$ at room temperature and does not vary too much over the range of interest for this work. The highconductivity Si plates have numerous narrow slots to create a large heat transfer surface area and allow heat to conduct between two separate flow regions within each plate. The low-conductivity glass spacers reduce streamwise heat conduction between the adjacent Si plates. This results in a large temperature gradient along the length of the heat exchanger when a hot stream and a cold stream pass through the heat exchanger in opposing directions. The heat exchanger is fab- 
ricated in a four-mask, six-step fabrication process. ${ }^{14}$ The $\mathrm{Si}$ slot structures are formed with a double-sided $\mathrm{KOH}$ etch of a (110) Si wafer, following which Pt resistance temperature detectors are patterned on selected dies for temperature measurement. The glass spacers are patterned by through-wafer $\mathrm{HF}: \mathrm{HNO}_{3}$ etching. The Si plate and the glass wafer are anodically bonded together and the bonded sandwich is diced. The dies are stacked and bonded with STYCAST 2850FT epoxy to form a heat exchanger. Figure 2(b) shows a photo of the micromachined perforated plate heat exchanger and a scanning electron microscopy (SEM) photo of the silicon slot structures etched by $\mathrm{KOH}$ on a (110) silicon wafer. The device has a cross section of $10 \times 10 \mathrm{~mm}^{2}$ and length of up to $35 \mathrm{~mm}$ (stack with 43 dies). A numerical model for the performance of the heat exchanger has been described by White et al. ${ }^{16}$

To accommodate cryogenic cooling, the expansion valve must have appropriate flow modulation capability over a wide range of operating temperatures. The valve must be able to withstand a large pressure difference as the gas expands through the valve and achieves the JT effect. The valve should be normally open or partially open to provide a fail-safe operation that does not block refrigerant flow and avoids excessive pressure buildup in the system. Several microvalve actuation schemes have been reported in the past, including electromagnetic actuation, ${ }^{17}$ electrostatic actuation, ${ }^{18-21}$ and thermal actuation, such as thermopneumatic, ${ }^{22,23}$ bimetallic, ${ }^{24-26}$ and shape memory alloys. ${ }^{27}$ Piezoelectric actuation is attractive because it can provide high force with relatively low power consumption. Figure 3(a) illustrates the microvalve design. The valve operates by pushing a bulk Si micromachined valve seat that is suspended from a Si frame against a Corning No. 7740 Pyrex glass substrate. The glass plate has inlet and outlet holes and allows the flow to pass through the gap between the valve seat and the glass plate. The flow rate is thus controlled by the size of the gap. A commercially available multilayered lead zirconate titanate (PZT) stack (Physik Instrumente, Germany, PL055) is used to drive the Si valve seat. The PZT stack has a footprint of $5 \times 5 \mathrm{~mm}^{2}$ and a height of $6 \mathrm{~mm}$. The detailed fabrication and assembly process of this valve were reported by Park et al. ${ }^{15}$ and a numerical model of this valve was reported by Brosten et $\mathrm{ll}^{28}{ }^{28}$ Macor $^{\mathrm{TM}}$, a machinable glass/mica ceramic that is also nonporous, was used for packaging the valve in order to minimize the temperature expansion mismatches between materials and thus avoid inhibition of valve operation. The fabricated microvalve with a ceramic enclosure [Fig. 3(b)] has a size of $1 \times 1 \times 1 \mathrm{~cm}^{3}$. The microvalve can operate at temperatures down to $80 \mathrm{~K}$ and only consumes $0.16 \mu \mathrm{W}$ of power in steady state. ${ }^{15}$

\section{INTEGRATION OF JT SYSTEM AND TEST FACILITY}

Figure 4(a) illustrates the simplified flow schematic of the test setup. A heat exchanger is mounted between a pair of stainless steel headers [Fig. 4(b)] that provide flow connections; one end is connected to a microvalve in order to as-

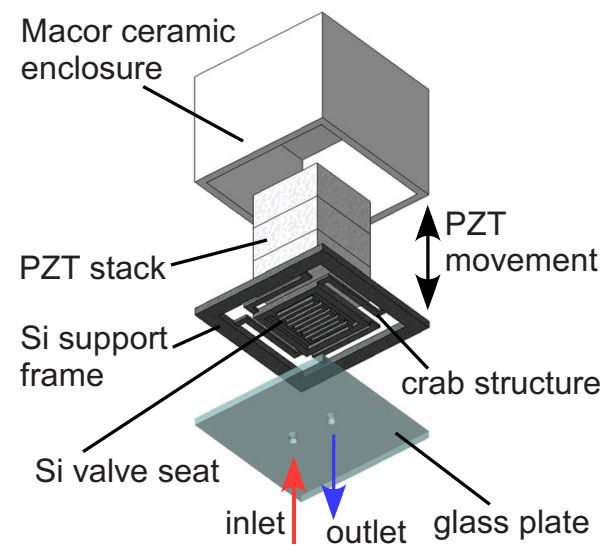

(a)

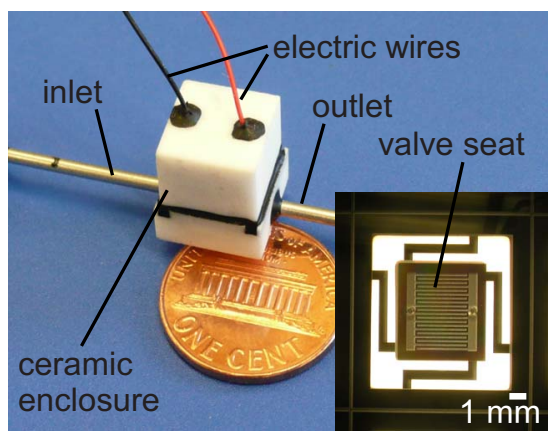

(b)

FIG. 3. (Color online) Piezoelectric microvalve design: (a) schematic diagram of the microvalve structure and (b) photo of a microvalve packaged with a ceramic housing. The overall size of housing is about $1 \times 1$ $\times 1 \mathrm{~cm}^{3}$. The inset shows a close-up of a fabricated valve seat.

semble a simple JT system. (The microvalve can be replaced by a jewel orifice for gas expansion.) A heater is attached to the copper tube between the microvalve and the cold inlet of the heat exchanger. The heater is not used for temperature control, but rather to simulate a heat load at the target. The entire JT system is placed into a high vacuum insulated Dewar [Fig. 4(b)]. An external compressor is used to drive a closed JT cycle by pressurizing the gas as it circulates back from the low-pressure returning stream. Ethane is used as the refrigerant in these proof-of-concept experiments because it has a large JT coefficient in the operating pressure range $(0-1 \mathrm{MPa})$ and therefore provides a large cooling power.

Temperatures and pressures at the hot inlet (of the heat exchanger), hot outlet, cold inlet, and cold outlet [respectively, denoted in Fig. 4(a) by subscripts 1, 2, 3, and 4] are measured using type $\mathrm{E}$ thermocouples that have absolute uncertainties of $\pm 1 \mathrm{~K}$. Digital pressure gauges are used to measure the absolute pressures at the hot inlet and cold outlet. Before the working fluid flows into the hot inlet of the heat exchanger, the mass flow rate is measured at room temperature using a Bronkhorst F-132M mass flow meter calibrated using nitrogen. The mass flow rate reading is converted to ethane based on formulas recommended by the manufacturer. The details for converting the reading and calculating the uncertainty in the flow rate were reported by White. ${ }^{29}$ 


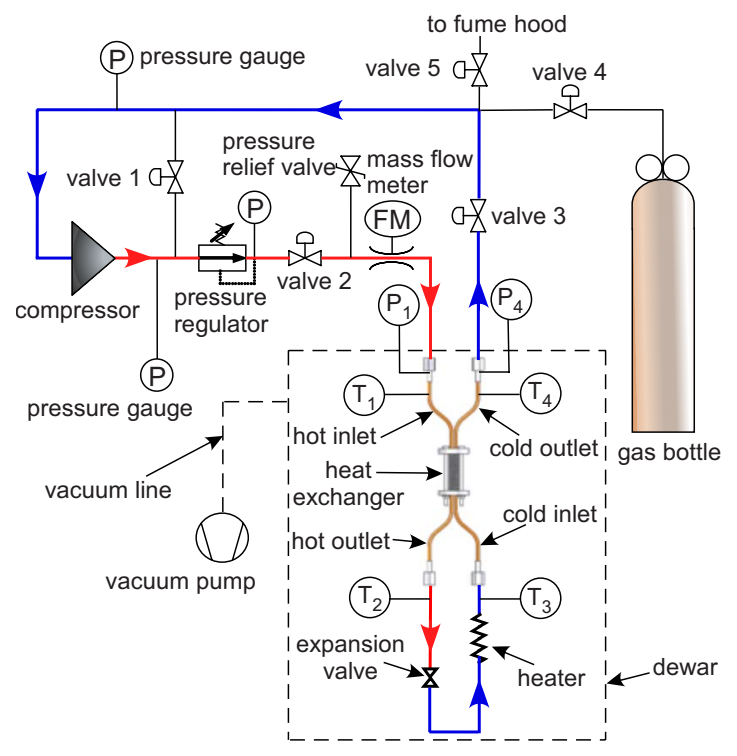

(a)

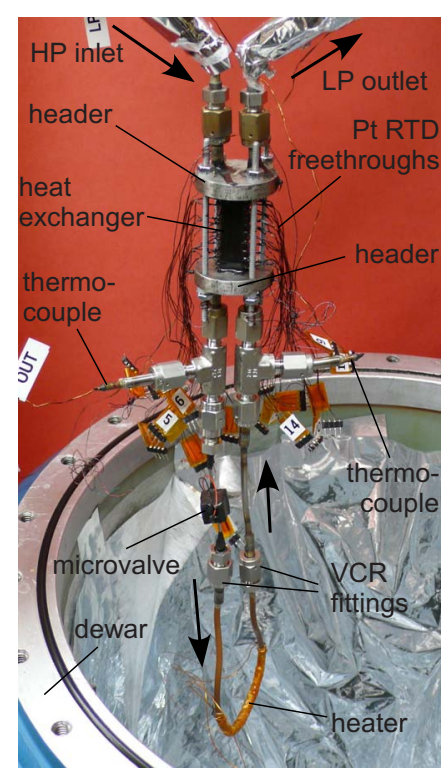

(b)

FIG. 4. (Color online) Test facility: (a) simplified schematic diagram of the test facility and (b) photo of the actual setup inside the Dewar.

Prior to the evaluation of the cooling system, a separate setup is used to first characterize the microvalve. This setup uses a Bronkhorst F-132M mass flow meter and pressure gauges located on both upstream and downstream of the microvalve. The mass flow rate and pressure difference across the valve are recorded at room temperature.

\section{EXPERIMENTAL RESULTS}

Figure 5 shows the typical results for ethane flow rate modulation by the microvalve. The input voltage range of the valve is from -30 to $100 \mathrm{~V}$. The relationships of mass flow rate and pressure difference for commercially available jewel orifices are also included in this plot. By comparison, the

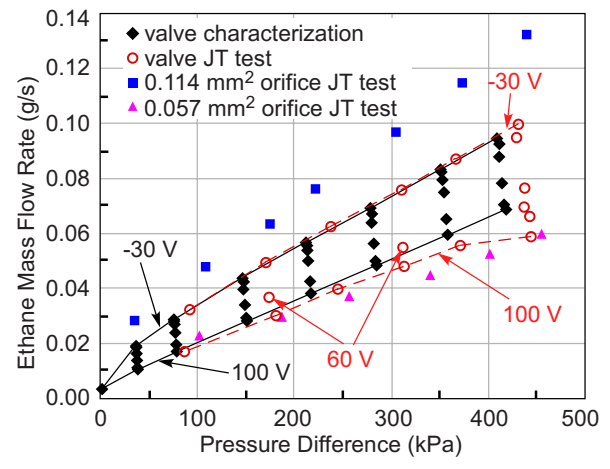

FIG. 5. (Color online) Ethane mass flow rate as a function of pressure difference in valve characterization test and JT tests. The mass flow rate is measured at room temperature in all tests.

microvalve provides a flow restriction that can vary between the value provided by a $0.057 \mathrm{~mm}^{2}$ (0.01 in. in diameter) jewel orifice and the value provided by a $0.086 \mathrm{~mm}^{2}(0.013$ in. in diameter) jewel orifice (provided by Bird Precision Corporation). As shown in Fig. 5, the flow rate range that the microvalve can modulate is more than $0.02 \mathrm{~g} / \mathrm{s}$ at a pressure difference of $430 \mathrm{kPa}$.

Figure 6 shows the temperature drop at the cold inlet from the hot inlet $\left(T_{3}-T_{1}\right)$ as a function of gas pressure between inlet and outlet $\left(P_{1}-P_{4}\right)$ in the JT test when the heater is off. All data were recorded when the system reached steady state. This figure also shows how the temperature can be adjusted by the flow modulation of the microvalve. The small flow modulation of the microvalve limits the modulation range of temperature to about 5-8 K. This is possibly due to excessive leakage flow at a high inlet pressure when the valve is supposed to be fully closed. The lowest steady-state temperature that the system can achieve at the cold end of the valve $\left(T_{3}\right)$ is about $254.5 \mathrm{~K}$ at $430 \mathrm{kPa}$ pressure difference between the hot inlet and the cold outlet with the valve input voltage at $-30 \mathrm{~V}$.

The system is able to sustain inlet gas pressure as high as $1 \mathrm{MPa}$ without leakage and can, in principle, achieve lower temperatures than those shown in Fig. 6. However, due to

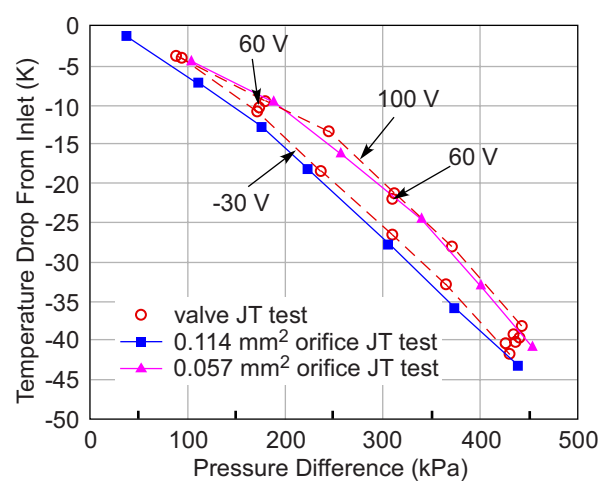

FIG. 6. (Color online) Temperature drop at the valve or orifice from inlet temperature as a function of pressure difference between inlet and outlet in the JT test. Since the input voltage of the microvalve is $-30-100 \mathrm{~V}$, the region between two dashed lines is the temperature region that the JT system can control at a given input pressure. 


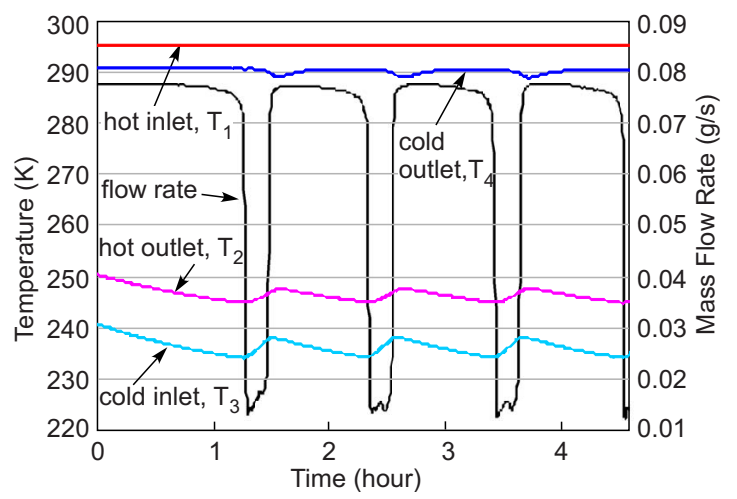

FIG. 7. (Color online) Transient response of the JT cycle when it is cooling down. The refrigerant flow is reduced by clogging as the temperature $T_{2}$ reaches around $244 \mathrm{~K}$ at the hot outlet, which is very close to the microvalve. This is mainly due to the impurities freezing within the microvalve.

impurities freezing inside the system, the refrigerant flow is significantly reduced when the hot outlet temperature $\left(T_{2}\right)$ reaches $244 \mathrm{~K}$. Similar clogging problems have been reported by Lerou et al. ${ }^{30}$ Figure 7 shows the transient response of this JT system at a pressure difference of $710 \mathrm{kPa}$ and illustrates the clogging problem. As the hot outlet temperature $\left(T_{2}\right)$ reaches $244 \mathrm{~K}$, the flow is reduced to nearly zero by impurities and the temperature increases due to parasitic heat loads. A possible source of contamination was the oil-lubricated compressor used in this system. Finally, when the system warms up and $T_{2}$ increases to $246 \mathrm{~K}$, the impurities melt, the flow can pass through the valve, and the temperature of the system drops down again. The system thus repeats the cooling cycle and the cold inlet temperature $\left(T_{3}\right)$ oscillates between 234 and $236.5 \mathrm{~K}$.

Ideally, the system should be able to reach a desired temperature within tens of minutes. As shown in Fig. 7, the cooling down rate of this JT system is very slow mainly because the thermal mass of the whole system is large compared to the cooling power. The total thermal mass of the metal components such as the headers, tubing, and fittings dramatically slows down the transient response of the JT system. (In the future, the heat exchanger and the micovalve should be integrated together in order to eliminate all unnecessary tubing and fittings and thus reduce total thermal mass to a much lower level.)

Figure 8 shows the experimentally measured cooling power that the system can provide when the input voltage of the microvalve is $-30 \mathrm{~V}$. For these tests, ethane mass flow rate was kept at $0.098 \mathrm{~g} / \mathrm{s}$ and the inlet pressure was around $535 \mathrm{kPa}$. The heater was turned on to simulate a heat load. The system provided cooling powers of $75 \mathrm{~mW}$ at $255 \mathrm{~K}$ and $150 \mathrm{~mW}$ at $258 \mathrm{~K}$. For a system that utilizes the micromachined heat exchanger without the microvalve, the estimated parasitic heat load at the low end of the temperature range is approximately $500 \pm 30 \% \mathrm{~mW}^{29}$ In practice, the losses are somewhat higher, particularly for the system under consideration here. The high end of the plot in Fig. 8 shows that the system had a cooling capacity of $800 \mathrm{~mW}$ at $297 \mathrm{~K}$, where the parasitic heat load approaches zero. If the efficiency of

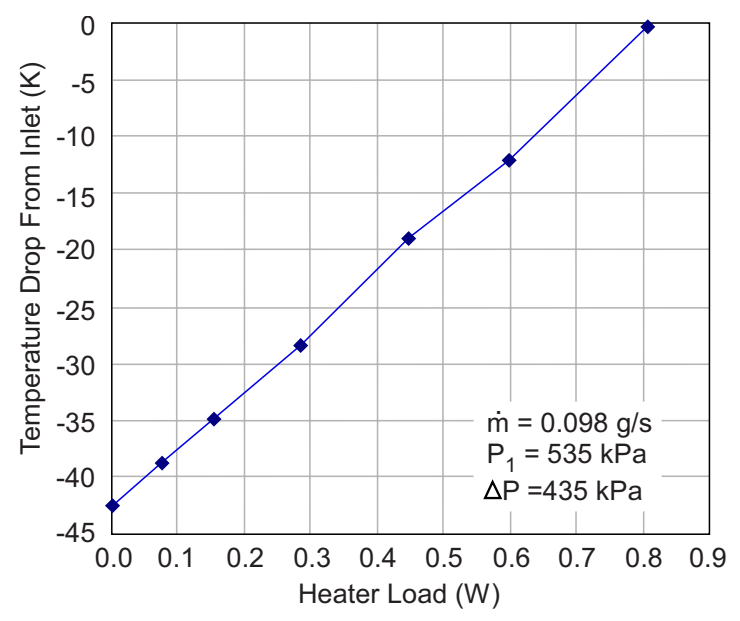

FIG. 8. (Color online) Temperature drop as a function of heater power. In this test, the inlet pressure was maintained at $P_{1}=535 \mathrm{kPa}$ and the input voltage of the valve was $-30 \mathrm{~V}$. The measured pressure difference $\left(P_{1}-P_{4}\right)$ is $435 \mathrm{kPa}$ and the ethane mass flow rate is $0.098 \mathrm{~g} / \mathrm{s}$.

the heat exchanger were constant, we would estimate the actual parasitic heat load to be approximately $700 \mathrm{~mW}$ based on the coldest test temperatures. Some of this load may be attributed to heat conduction through tubing and the electrical leads embedded within the heat exchanger and the microvalve. However, there are also multiple factors that affect the efficiency of the JT cycle as the cold end temperature decreases. These include, for example, the change of the JT coefficient, the increase of the conductivity of $\mathrm{Si}$, and the increase of parasitic heat load, which includes both conduction and radiation. Hence, the results shown in Fig. 8 are sensitive to the test conditions and not necessarily representative of largest performance achievable by the device.

\section{CONCLUSIONS}

This effort has demonstrated a closed loop JT cooling system using a micromachined perforated plate Si/glass heat exchanger and a piezoelectric expansion microvalve for modulating the refrigerant flow and thus the cooling temperature. The microvalve opening can be adjusted so that it is approximately equivalent to a commercially available jewel orifice ranging from $0.057 \mathrm{~mm}^{2}$ (0.010 in. in diameter) to $0.086 \mathrm{~mm}^{2}$ (0.013 in. in diameter). With ethane as the refrigerant, the system provided cooling powers of $75 \mathrm{~mW}$ at $255 \mathrm{~K}$ and $150 \mathrm{~mW}$ at $258 \mathrm{~K}$. Experiments showed that the system could achieve $254.5 \mathrm{~K}$ at $430 \mathrm{kPa}$ pressure difference at steady state and $234 \mathrm{~K}$ at $710 \mathrm{kPa}$ in transient mode. Due to impurities freezing inside the valve, the system was clogged as the hot outlet temperature $\left(T_{2}\right)$ reached around $244 \mathrm{~K}$. With ethane as the refrigerant, it should be possible to achieve minimum temperature in the proximity of $185 \mathrm{~K}$. With the use of a more purified supply of refrigerant and improved thermal insulation to reduce parasitic heat loads, it is anticipated that a lower temperature is achievable because the system is robust enough to sustain inlet pressure as high 
as $1 \mathrm{MPa}$ without internal and external leakages. In the long term, a system of this type may be used in a distributed cooling network or in a cryosurgical tool.

\section{ACKNOWLEDGMENTS}

The authors gratefully acknowledge Sanford Klein for important contributions to the concepts and modeling methodologies of the devices described in this article and James Maddocks for discussions about the test setup. Both Klein and Maddocks are at the University of Wisconsin, Madison. This work was funded in part by a grant from the U.S. National Institutes of Health (Grant No. NIH/NINBS R33 EB003349-05).

${ }^{1}$ B. Collaudin and N. Rando, Cryogenics 40, 797 (2000).

${ }^{2}$ H. J. M. ter Brake and G. F. M. Wiegerinck, Cryogenics 42, 705 (2002).

${ }^{3}$ M. Klauda, et al., IEEE Trans. Microwave Theory Tech. 48, 1227 (2000).

${ }^{4}$ A. A. Gage, Surg. Gynecol. Obstet. 174, 73 (1992).

${ }^{5}$ Z. H. Chang, J. J. Finkelstein, and J. G. Baust, in Recent Advances in Cryogenic Engineering, edited by J. P. Kelley and J. Goodman (ASME, New York, 1993), pp. 45-55.

${ }^{6}$ J. Dobak, Adv. Cryog. Eng. 43, 889 (1998).

${ }^{7}$ B. Z. Maytal, Adv. Cryog. Eng. 43, 911 (1998).

${ }^{8}$ E. D. Marquardt, R. Radebaugh, and J. Dobak, Adv. Cryog. Eng. 43, 903 (1998).

${ }^{9}$ W. A. Little, Physica B 109-110, 2001 (1982).

${ }^{10}$ J. Burger, H. Holland, J. Seppenwoolde, E. Berenschot, H. ter Brake, J. Gardeniers, M. Elwenspoek, and H. Rogalla, Cryocoolers 11, 551 (2001).

${ }^{11}$ P. P. P. M. Lerou, H. J. M. ter Brake, J. F. Burger, H. J. Holland, and H. Rogalla, J. Micromech. Microeng. 17, 1956 (2007).

${ }^{12}$ P. Bradley, R. Radebaugh, M. Huber, M.-H. Lin, Y. Lee, and V. Bright, Proceedings of the 15th International Cryocoolers Conference, Long Beach, CA, 2008 (unpublished), pp. 425-432.

${ }^{13}$ W. Zhu, M. J. White, G. F. Nellis, S. A. Klein, and Y. B. Gianchandani, Proceedings of the IEEE International Conference on Solid-State Sensors and Actuators, Denver, CO, June 2009 (unpublished), pp. 2417-2420.

${ }^{14}$ W. Zhu, M. J. White, G. F. Nellis, S. A. Klein, and Y. B. Gianchandani, J. Microelectromech. Syst. 19, 38 (2010).

${ }^{15}$ J. M. Park, R. P. Taylor, A. T. Evans, T. R. Brosten, G. F. Nellis, S. A. Klein, J. R. Feller, L. Salerno, and Y. B. Gianchandani, J. Micromech. Microeng. 18, 015023 (2008).

${ }^{16}$ M. J. White, G. F. Nellis, S. A. Klein, W. Zhu, and Y. B. Gianchandani, J. Heat Transfer 132, 111801 (2010).

${ }^{17}$ S. C. Terry, J. H. Jerman, and J. B. Angell, IEEE Trans. Electron Devices 26, 1880 (1979).

${ }^{18}$ P. Dubois, B. Guldimann, and N. F. de Rooij, Proc. SPIE 4560, 217 (2001).

${ }^{19}$ J. Collier, D. Wroblewski, and T. Bifano, J. Microelectromech. Syst. 13, 912 (2004).

${ }^{20}$ N. Vandelli, D. Wroblewski, M. Velonis, and T. Bifano, J. Microelectromech. Syst. 7, 395 (1998).

${ }^{21}$ M. A. Huff, J. R. Gilbert, and M. A. Schmidt, Proceedings of the IEEE International Conference on Solid-State Sensors and Actuators, Yokohama, Japan, June 1993 (unpublished), pp. 98-101.

${ }^{22}$ M. J. Zdeblick and J. B. Angell, Proceedings of the IEEE International Conference on Solid-State Sensors and Actuators, Chicago, IL, June 1987 (unpublished), pp. 437-439.

${ }^{23}$ C. A. Rich and K. D. Wise, J. Microelectromech. Syst. 12, 201 (2003).

${ }^{24}$ P. W. Barth, C. C. Beatty, L. A. Field, J. W. Baker, and G. B. Gordon, Proceedings of the IEEE Solid-State Sensor and Actuator Workshop, Hilton Head Island, SC, June 1994 (unpublished), pp. 248-250.

${ }^{25}$ P. W. Barth and G. Gordon, U.S. Patent No. 5,333,831 (August 2, 1994).

${ }^{26}$ S. Messner, M. Muller, V. Burger, J. Schaible, H. Sandmaier, and R. Zengerle, Proceedings of the IEEE International Conference on Micro Electro Mechanical Systems, Heidelberg, Germany, January 1998 (unpublished), pp. 40-44.

${ }^{27}$ M. Kohl, D. Dittmann, E. Quandt, and B. Winzek, Sens. Actuators, A 83, 214 (2000).

${ }^{28}$ T. R. Brosten, J. M. Park, A. T. Evans, K. Rasmussen, G. F. Nellis, S. A. Klein, J. R. Feller, L. Salerno, and Y. B. Gianchandani, Cryogenics 47, 501 (2007).

${ }^{29}$ M. J. White, MS thesis, University of Wisconsin-Madison, 2008.

${ }^{30}$ P. Lerou, H. ter Brake, H. Holland, J. Burger, and H. Rogalla, Appl. Phys. Lett. 90, 064102 (2007). 